\title{
A CONVIVÊNCIA COM O FANTASMA DO CÂNCER
}

\author{
M aria A parecida SALCI ${ }^{b}$, Sonia Silva M ARCON ${ }^{c}$
}

\section{RESUM 0}

A proposta deste estudo é compreender como mulheres com câncer e seus familiares convivem e enfrentam a doença após o término do tratamento. Como estratégia teórico-metodológica foi utilizado o Interacionismo Simbólico e a Teoria F undamentada nos Dados. Os dados for am coletados no período de março a novembro de 2005, junto a vinte indivíduos, sendo dez mulheres portadoras de câncer e seus familiares, os quais constituíram três grupos amostrais. I dentificamos que conviver com o câncer desencadeia uma série de emoções, entre elas, o medo de que um dia uma recidiva possa se instalar, o que torna a realização de exames pós tratamento algo consideravelmente estressante. Conviver com 0 câncer significa preocupar-se com ele e buscar estratégias para uma boa convivência. 0 estudo nos per mite compreender esse contexto e repensar al gumas estratégias de cuidados a partir dessas consider ações.

D escritores: N eoplasias. Enfermagem oncológica. Saúde da mulher. Saúde da família.

\section{RESUMEN}

E I objetivo deeste estudio es entender cómo las mujeres y sus familias viven con el enfrentamiento diario de cáncer después del tratamiento. Como estrategia teórica y metodol ógica se utilizó el Interaccionismo Simbólico y la T eoría F undamentada en los datos. L os datos fuer on recolectados a partir de marzo a noviembre de2005, con veinteindividuos, diez mujeres que sufren de cáncer y sus familiares, divididos en tres grupos. Convivir con el cáncer desencadena una variedad de emociones, entre ellas el temor de la recaída, lo que hace que las pruebas delaboratorio después del tratami ento sean al go bastante estresante. Vivir con el cáncer si gnifica preocuparse con él y buscar estrategias para una buena vida. El estudio nos permite comprender este contexto y reflexionar sobre algunas estrategias para la atención de estas consideraciones.

Descriptores: N eoplasias. E nfermería oncológica. Salud dela mujer. Salud de la familia.

T ítulo: Viviendo con el fantasma del cáncer.

\section{ABST RACT}

The purpose of this study is to understand how women and their families live with the daily confrontation of cancer after the end of the treatment. Symbolic Interactionism and D ata T heory w ere used as a theoretical and methodological framew ork. D ata w erecollected from $\mathrm{M}$ arch to $\mathrm{N}$ ovember 2005, from tw enty subjects, with ten women suffering from cancer and their relatives divided into three samplegroups. To live with cancer triggers a variety of emotions, such as the fear that one day the di sease will return. T his makes laborator y tests after treatment considerably stressful. To live with cancer means w or rying about the disease and seeking strategies to cope with it. The study all ow s us to understand this situation and rethink some of the caring strategies.

D escriptors: N eoplasms. O ncologic nursing. W omen's health. F amily health.

T itle: Coping with the specter of cancer.

\footnotetext{
a Parte da dissertação de M estrado apresentada em 2005 ao Programa de Pós-Graduação em Enfermagem da Universidade Estadual de M aringá (UEM).

b M estre em Enfermagem, D ocente do D epartamento de Enfermagem da UEM, M aringá, Paraná, Brasil.

c D outora em F ilosofia da Enfermagem, D ocente do Departamento de Enfermagem da U E M , M aringá, Paraná, Brasil.
} 


\section{INT RODUÇÃO}

0 diagnóstico de câncer quase sempreéacompanhado por um estigma aterrorizante, pois desperta nas pessoas sentimentos como: raiva, medo, angústia, impotência, desamparo, tristeza, desespero e principalmente medo da morte ${ }^{(1)}$. As metáforas ag regadas ao câncer geral mente representam uma série de fusões simbólicas que podem provocar efeitos desagradáveis, dependendo da maneira como os doentes percebem a sua própria condição e de como as outras pessoas agem em relação a eles ${ }^{(2)}$.

No entanto, com os avanços nos métodos de diagnóstico e de tratamento na área da medicina a partir dos anos 50, iniciou-se uma mudança considerável nos significados e formas de enfrentamento da doença, o que contribuiu para o aumento do número de sobreviventes e do tempo de sobrevida dos portadores de câncer ${ }^{(3)}$.

0 vivenciar de um câncer desencadeia uma nova reflexão sobre a vida, pois, uma vez instalada a doença, a pessoa necessita de uma série de mudanças nos hábitos de vida e entre elas um acompanhamento rigoroso de seu estado de saúde, afinal as recidivas da doença são inevitáveis em alguns casos.

A descoberta deste diagnóstico ocorre dentro de um contexto familiar, desencadeando mudanças na família como um todo, de forma que os familiares, em maior ou menor grau, são afetados pelas situações decorrentes da doença.

A trajetória percorrida após o diagnóstico de câncer envolve inicialmente uma fase de conflito emocional desencadeada pela descoberta da doença; as fases seguintes são acompanhadas de percepções sobre mudanças e al ter ações relacionadas a vários aspectos da vida, decorrentes da doença e dos tratamentos e por fim, uma fase de adaptação para viver no mundo como portador de câncer, 0 que implica a adoção de um novo estilo de vida(4).

Diante destas características das neoplasias malignas, objetivamos neste estudo compreender como mulheres com câncer e seus familiares convivem e enfrentam a doença após o término do tratamento.

\section{TRAJETÓRIA METODOLOGICA}

E studo do tipo exploratório, de natureza qualitativa que adotou o I nter acionismo Simbólico (IS) como referencial teórico e a T eoria $\mathrm{F}$ undamentada nos $D$ ados (TF D) como referencial metodológico. O IS é uma perspectiva teórica centrada na interação humana, segundo a qual os seres humanos agem conforme os significados que atribuem às coisas $^{(5)}$. A T FD, por sua vez, tem como propósito construir um model o teórico que facilite o entendimento dos fenômenos sociais, a partir da perspectiva dos sujeitos investigados ${ }^{(5)}$.

0 estudo foi realizado em M aringá, Paraná, no período de março a novembro de 2005. Os dados foram coletados junto a 20 indivíduos, sendo 10 mulheres portadoras de câncer e um de seus familiares indicados por elas, compondo-se três grupos amostrais. 0 primeiro grupo foi constituído por cinco mulheres que estavam realizando tratamento radioterápico, o segundo, por três que haviam apresentado metástase e estavam realizando o segundo tratamento radioterápico, sendo que uma del as já havia integ rado o primeiro grupo; e 0 terceiro, por três mulheres que haviam passado por tratamento há mais de cinco anos.

$\mathrm{Na}$ composição dos grupos, foram respeitados os critérios de amostragem e saturação teórica conforme proposto pela T F D ${ }^{(6)}$. A mostragem teórica é o processo no qual o pesquisador após coletar, codificar e analisar os dados de cada grupo amostral decide quais dados ainda necessitam ser coletados e onde podem ser encontrados. A saturação teórica refere-se ao momento em que não são mais encontrados dados novos ou adicionais em deter minado grupo(6).

As mulheres do estudo tinham idade entre 27 e 50 anos e níveis de escolaridade e social diversos e, embora não nos importasse a local ização da doença, mas sim o significado atribuído a ela, houve predomínio de mulheres com câncer de mama (oito casos). D as outras duas, uma tinha linfoma de Hodgkin e outra, câncer de colo de útero. Os familiares entrevistados foram quatro filhas, duas irmãs, dois esposos, uma mãe e uma prima.

0 contato com as mulheres ocorreu a partir dos registros em uma clínica de radioterapia. 0 primeiro contato para solicitação de participação no estudo foi por telefone. As entrevistas abertas ocorreram nos domicílios, previamente agendadas, com a seguinte questão norteadora: "O que mudou em seu contexto familiar após o diagnóstico de câncer?". A pós a transcrição na íntegra das entrevistas e leitura das mesmas, iniciou-se o processo de codificação aberta e categorização dos dados. 
0 projeto de pesquisa foi aprovado pelo Comitê Permanente de É tica em Pesquisa com Seres H umanos da U niversidade Estadual de M aringá (parecer $\mathrm{n} 0045 / 2005$ ). Todos os participantes assinaram o Termo de Consentimento Livre e Esclarecido e, para assegurar o anonimato das informantes, foram utilizados nomes fictícios.

A análise dos dados per mitiu a construção de uma teoria substantiva, que originou uma dissertação de mestrado, cujo fenômeno central foi intitulado: "O enfrentamento do câncer em família", constituído por três processos: a descoberta da doença; a percepção das mudanças após o diagnóstico de câncer e a convivência com a doença. Os resultados apresentados na presente comunicação integram o terceiro processo.

\section{APRESENT AÇÃO E DISCUSSÃO DOS RESULTADOS}

Q uando as mulheres conseguem super ar com êxito os tratamentos propostos para combater 0 câncer, se deparam com a nova etapa "ter que conviver com o câncer" visto que, após o tér mino dos tratamentos, precisam certificar-se da resposta do organismo à doença; pois sendo o câncer uma doença crônica, seu controle exige obser vação constante e seguimento prolongado(7).

A o receber o diagnóstico de câncer, a mulher e sua família passam por experiências nunca antes vivenciadas ${ }^{(8)}$. A obrigatoriedade de ter que conviver com 0 câncer faz com que a mulher vivencie uma nova rotina de vida. Ao manifestarem suas experiências, as mulheres revelaram, que mesmo após o término dos tratamentos propostos, ainda havia um longo caminho a ser percorrido. Esta percepção era advinda da necessidade de se adequar em a um estilo de vida marcado por preocupações e pela prática rigorosa e periódica de realização de exames para detecção precoce de novos focos da doença.

Vale destacar que, o fato de a maioria das mulheres desse estudo serem portadoras de câncer de mama, se justifica uma vez que esse tipo de câncer é o mais freqüente entre as mulheres além do fato de o mesmo provocar mutilações e deixar marcas físicas e emocionais. T odos esses fatores em conjunto repercutem de forma marcante na vida delas e isso suscita a necessidade de serem desenvolvidos estudos que apontem de que for ma os profissionais precisam agir em relação a elas justifi- cando o fato de a maioria dos estudos disponíveis na liter atura abordarem este tipo de câncer.

Entretanto, verificamos que as mulheres que são acometidas por outros tipos de neoplasias também passam por todos os processos suscitados pelo fenômeno central - o enfrentamento do câncer em família - de modo extremamente similar.

Esta vivência deu origem ao sub-processo identificado como a convivência com o fantasma do câncer, o qual é constituído por duas categorias: a necessidade de continuidade dos exames e a necessidade de convivência com o câncer.

\section{A necessidade de continuidade dos exames}

As mulheres que tratam um câncer enfrentam uma longa jor nada nos consultórios médicos, clínicas e laboratórios para realizar uma série de exames que conduzirão às novas etapas de suas vidas.

A gora eu terminei o tratamento, ainda não fui à médica, vou hoje à tarde e provavelmente ela vai pedir os exames [ ...] (T ânia).

A ssim, real izar exames labor atoriais e de imagem torna-se uma necessidade em suas vidas, a qual é acompanhada de perto pela família. A dentrar essa nova fase é um caminho que gera sentimentos de insegurança, medo, ansiedade, angústia e temor ante os resultados dos exames, visto que os mesmos determinarão o caminho a ser seguido, que poderá ser programado de maneira muito diferente ao esperado, pois é incerto o que o futuro lhes reserva:

[ ...] um frio na barriga, por maisféquevocêtenha, dá um medo, medo mesmo (T ânia).

De certa forma, estes sentimentos também estão presentes nas outras vezes em que realizam exames:

M eu coração acelera quando sei que tem quefazer exames de novo, sei queo médico vai pedir os exames, você fica com medo do resultado. T enho muita féque os exames não vão dar nada (M ônica).

M esmo tendo fé e acreditando que seus exames estarão normais, elas se angustiam e sentem temor só de pensar na possibilidade de al guma alteração nos resultados. Isto porque todos os pro- 
blemas que apareceram após o diagnóstico de câncer são associados, por elas, a uma possível metástase. Observa-se entre as mesmas a busca por esclarecimentos, ou seja, uma inter pretação daquele diagnóstico o mais rápido possível. Por isso, manifestam a vontade de voltar rapidamente ao médico para terem uma garantia de que estão bem:

[ ...] estou traumatizada, sinto caroços no meu peito, nas costas. Toda hora tenho vontade de estar dentro do consul tório do médico. E nquanto eu não chegar no mé dico e ele falar que não tenho nada, que estou curada... E u sei que tenho fé, que tenho $D$ eus, mas preciso me livrar disso. É um sentimento que só quem passa mesmo por uma quimioterapia para saber [ ...] (A na M aria).

A té as mulher es que ter minaram o tratamento há algum tempo e que de certa forma sentem que pelo menos momentaneamente ganharam a batal ha contra o câncer, vivem sempre em estado de alerta com relação à doença, pois sentem medo de necessitarem submeter-se novamente a um tratamento quimioterápico.

$\mathrm{N}$ o primeiro momento que fiquei sabendo do câncer 0 medo era morrer, hoje, o medo é 0 tratamento, a gente já tem a noção do que é uma quimioterapia, do que é uma radioterapia, então já fico pensando no tratamento [ ...] . É sofrido demais (M ônica).

É interessante observar que após ser submetida aos diferentes tratamentos para o câncer, as pessoas tendem a mudar o significado que atribuíam ao câncer, o qual deixa de ser percebido única e exclusivamente como sinônimo de morte. No entanto, um estudo realizado com mulheres com metástase e em tratamento quimiterápico pela segunda vez ${ }^{(9)}$, pontua que a repetição representa para elas al go amedrontador e que o medo da morte évivenciado de forma tão significativa que a mulher tem grande possibilidade de apresentar alterações psicossomáticas.

A periodicidade dos exames, após o término do tratamento, é regular e contínua, embora para o mesmo tipo de câncer alguns médicos conduzem esse período em interval os diferentes, como afirma:

[ ...] no começo era de dois em dois meses, depois de três em três, depois de seis em seis meses e agora é de ano em ano ( $G$ isele).
Sentimentos negativos relacionados à possibilidade do surgimento de metástase podem persistir e acompanhar as mulheres por um longo período. Há dois anos e 10 meses $\mathrm{G}$ isele teve o primeiro diagnóstico de câncer e relata que não fica bem ao fazer os exames de rotina:

[ ...] vocêvai fazer os exames, mas vocêvai com aquele aper to no coração, deprimida! (G isele).

E sse sentimento se justifica, afinal, foi durante os exames de rotina e depois os periódicos que ela se descobriu portadora de câncer por duas vezes. Para outras mulheres, por exemplo, a tensão era tamanha que chegava a dificultar o exame:

E u sentava lá [ no consultório médico] eficava igual uma corda de violão, bem esticada. P rincipalmente quando 0 doutor, falava: "olha, agora a gentetem quefazer um exame, tem queapalpar... relaxa" (Alessandra).

Entre as mulheres que tiver am câncer há mais de cinco anos, a preocupação e a ansiedade parecem diminuir com o passar do tempo e elas vão ficando mais tranqüilas ao terem que realizar os exames de rotina:

É uma sensação estranha, nem sei como explicar, mas eu me preocupava sim. Toda vez queia fazer o preventivo era rezando, pedindo a $D$ eus que o resultado viesse normal, era angustiante, até que não pegava o resultado na mão [ ...] . D epois quevi quetoda vez defazer os exames, dava sempre a mesma coisa e o médico falava que era normal, aí fui me tranqüilizando. M as só com o passar do tempo mesmo (Regiane).

Não obstante, algumas mulheres ficam extremamente ansiosas no início e associam tudo 0 que aparece de "estranho/ diferente" no corpo ao câncer:

N o começo tudo assusta, até uma dor de cabeça: "ah, 0 queéisso!?", mas com o tempo vocêjá não associa mais. É claro, a gente sabe que se tiver uma dor constante, ela precisa ser investigada, [ ...] só que se a gente for pensar assim, vocêvai esquecer até de viver, então você vai ficar pensando no amanhã? (Alessandra).

Alguns familiares também relataram que a ansiedade está mais presente nos primeiros anos após o tratamento, e, que com o passar do tempo, vai diminuindo gradativamente, até que se torne uma rotina realizar os exames anual mente: 
E u ficava meio receosa, pensando "será quenão vai dar mais nada?", apesar dela ter tirado a mama inteira, mas ea outra? P orque via pessoas quetinha voltado na outra, vi gente que tevenas duas ao mesmo tempo. M as agora fico mais tranqüila [ ...] (F ilha de Alessandra).

Quando a mulher se depara com um exame mais específico, ela sente medo e fica insegura, mesmo estando em remissão há mais de cinco anos:

[ ...] hoje eu fico ansiosa só quando eu tenho que fazer uma biópsia mesmo, daí eu fico, mas os outros exames não (Camila).

Camila ainda acredita que, nesses casos, por mais que o tempo passe, sempre associará novas alter ações com a doença:

Ah... é uma coisa assim, parece um "fantasma", que nunca vai sair de dentro de você, acho que nunca sai, acho que você pode estar lá no finalzinho da vida, vai ser sempre assim. Q uando vocêtem uma dor e tem que fazer uma biópsia, você sempre fica com medo, então não adianta, porquei sso eu acho que acontece com qualquer um que já teve a doença, é, esse "fantasma" não sai não [ ...] (Camila).

É notória, no depoimento de Camila, a mudança no significado que ela atribui ao câncer após tê-lo vivenciado. Esta mudança é experienciada por muitas mulheres que dão indícios de que o câncer passa a ser um fantasma que rondará suas vidas mesmo que já tenham terminado com êxito todos os tratamentos e encontram-se bem de saúde há bastante tempo.

0 câncer como fantasma também é concebido pelos familiares já que qualquer alteração suspeita no corpo da mulher eles também associam ao câncer e relembram as experiências já vividas:

E sses tempos ela teve um carocinho na mama, aí me preocupei. Será que vai começar tudo de novo? $\mathrm{N} \mathrm{a}$ mesma pessoa [ ...] . A té sair os exames ever o que era, fiquei apreensiva, pensativa, lembrando tudo de novo [ ...] (F ilha de Regiane).

A sensação de que o familiar terá que conviver com o câncer para sempre também é real, como relata a irmã de Camila, que inclusive nos mostra que o "fantasma câncer" rodeia os pensamentos dos familiares:
A cho que em pensamento, sempre vai ter uma coisinha quevai ficar lá no fundo... P orquequando vocêvêuma reportagem, uma pessoa falando, do que você lembra? J á lembra nela. E ntão não adianta, ficou uma marca, né. F ica uma marca (I rmã de Camila).

$\mathrm{N}$ essa per spectiva, para algumas mulheres, a recordação do câncer está frequentemente presente em suas vidas e na de seus familiares, desde que descobriram o diagnóstico pela primeira vez:

[ ...] é assim, você acorda lembrando que tem isso, é 0 dia todo pensando [ ...] a família inteira éassim, meus irmãos que moram lá em Porto Velho, falam: depois que deu isso em você eu não esqueço isso um minuto (M aria Santa).

0 medo permanece latente nessas pessoas, durante toda a história da doença e trajetória de luta pela vida, medo esse que inclui: ouvir que tem câncer, enfrentar os comentários da família e dos amigos, da cirurgia, de se ver e se mostrar mutilada pelas sequelas da cirurgia, de não saber se cuidar e se tornar dependente, de fazer o tratamento complementar, da doença voltar, de não aguentar e morrer ${ }^{(10)}$. 0 medo da morte está relacionado à incerteza do futuro o que inclui a possibilidade de não realizar projetos de vida como 0 de poder: acompanhar o crescimento dos filhos, conhecer netos, usufruir de aposentadorias entre ou$\operatorname{tros}^{(11)}$.

A ssim, o sentimento de incerteza e preocupação com a possibilidade de uma recidiva passa a ser uma constante na vida das mulheres e de seus familiares, desde o diagnóstico até a continuidade do controle da doença ${ }^{(12)}$.

\section{A necessidade de convivência com o câncer}

Conviver com o câncer implica continuar a trajetória de vida sabendo que já foi portadora de uma doença grave. Assim, as mulheres ficam mais atentas a tudo o que acontece de diferente em seu corpo, buscando ajuda médica mais rapidamente.

As famílias também ficaram mais atentas e em "estado de al erta" em relação às queixas de problemas de saúde em seus membros, como percebemos em suas falas:

[ ...] o que mudou muito na minha família toda, éque todas as mulheres começaram a se precaver mais, ficaram mais atentas, faz em exames de rotina, vão sempre 
ao médico, principalmente as minhas ir mãs, sobrinhas também (Regiane).

N essa nova fase de suas vidas, em que sobreviveram ao diagnóstico de câncer e aos efeitos indesejáveis dos tratamentos antineoplásicos, o significado do surgimento de al ter ações no corpo acaba sendo mais valorizado pelas mulheres e seus familiares, uma vez que se tornaram mais atentos aos problemas de saúde, pois, quando surge algo diferente, não ficam à espera de uma evolução e rapidamente procuram um médico para esclarecer o problema que suscita-Ihes preocupações e angústia, o que é revelado no depoimento:

[ ...] e quando você sente uma dor, você fica com a cabeça "perturbadinha". F ica! Seeu sentir uma dor aqui na ponta do dedo, já corro no médico. A té ontem fui no doutor, estava com dor nas costas, mas elenão pode me atender... (G isele).

M esmo quando a mulher está bem, considerando que obteve sucesso no tratamento equeleva uma vida normal, ao ficar sabendo de um caso de recidiva da doença ou de alguém que morreu pelo diagnóstico de câncer, ela sofre, pois se fragiliza e, consequentemente, sente-se mais próxima da doença:

0 meu câncer foi na mesma época que o da $M$ aria R ita do R oberto Carlos, ela foi [ ...] , mesmo com tanto dinhei ro quetinha para fazer detudo pela vida dela [ ...] . $M$ eu tio também teve um câncer no intestino na mesma época e faleceu. Ah, não sabia nem o que pensar, na hora fiquei arrasada (Camila).

M esmo ter minado os tratamentos com sucesso, ao relembrar o câncer, as mulheres podem mobilizar uma série de sentimentos, que precisam ser trabalhados internamente de maneira paulatina, como depreendemos no relato:

Vem na minha cabeça lembranças e eu mudo de pensamento, falo: "não quero lembrar isso". T em que evitar pensar! N ão gosto de passar em frenteda dínica, quando tenho que levar os exames, conversar com a médica, dá ar repio só de ir lá, sinto cheiro dos medicamentos, eles têm um cheiro forte, as pessoas que não passaram por isso não sentem... (T ânia).

Com o aumento da sobrevida após os tratamentos, é fundamental que compreendamos a experiência de se viver com o câncer, pois a presença constante da incerteza aparece como elemento importante nas vidas dessas mulheres e se manifesta, muitas vezes, através do medo de uma recorrência da doença(13).

Entretanto, sendo inevitável depararem-se, em al gum momento, com casos de pessoas que não obtiveram o mesmo sucesso que o seu e morreram, as mulheres tentam arrumar estratégias para não pensarem na doença. P rocuram não lembrar o fato, e exercitam mental mente para focal izar em os pensamentos em um futuro promissor e não no passado, como expressa a depoente:

Passado é passado, não quero lembrar e não vou lembrar, passou! Vida nova [...] Quando lembro me dá uma coisa ruim, às vez es lembro de momentos que passei, quero esquecer aquilo (T ânia).

Todavia, mesmo já estando em remissão da doença há mais de cinco anos, ficar comentando sobre 0 assunto não é algo agradável:

N ão meimporto defalar [ do câncer] , mas pareceque te dá uma agonia ficar falando muito. L ógico, quando vejo alguém procuro sempre animar, mas procuro não ficar lembrando disso. P rocuro esquecer (Camila).

Ao comentar sobre o passado, transmitem sentimentos de pesar, que ainda habitam no âmago de seu ser, buscam desvincular esses pensamentos negativos e agradecer a D eus por estarem vivas:

[ ...] daí, vocêpensa: "ah! D eus poupou a minha vida", então se E le poupou é porque não chegou minha hora, acho que ainda tenho mais coisas para fazer aqui [ ...] (Camila).

A fé é uma fonte de apoio para o enfrentamento do diagnóstico pelo paciente e seus familiares, bem como para conseguir suportar os desafios provocados pel os diver sos tratamentos, ou até mesmo confortarem-se diante da impossibilidade de cura.

E studo com adultos portador es de metástase, em tratamento quimioterápico, preconiza que 0 despertar da fé indica uma maneira de amenizar os sentimentos angustiantes experienciados pelos pacientes oncológicos com possibilidade de morte(14).

Ainda com relação ao aumento da fé do paciente que vivencia um câncer, vale destacar que 
"quando o indivíduo se encontra diante de uma situação desesperadora, na qual a morte é tida como um acontecimento praticamente inevitável, a crença na existência de um ser superior é vivificada [...]" ${ }^{\prime \prime(15)}$.

M aria Santa, além de não gostar de falar sobre a doença, gostaria que as pessoas que a abordam não focal izassem o diálogo no câncer, como revela em sua fala:

[ ...] as pessoas, às vezes, ficam insistindo, mas tem hora que eu não quero só ficar falando disso, não quero mais falar só da doença (M aria Santa).

A preendemos nos discursos aqui elencados que o sofrimento provocado em al gumas mulheres ao recordarem da doença, pode estar relacionado ao significado atribuído ao câncer, pois o mesmo parece permanecer imutável após a pessoa tê-lo vivenciado e, mesmo estando bem, ou seja, sem sinais eminentes da doença, o sofrimento ainda as amedronta:

Sefalar assim: "Camila vocêestá com câncer de novo", lógico que vou lutar, vou fazer todos os tratamentos, mas lá no fundo vocêsempretem aquelefantasma, você nunca vai falar: "ah, eu não tenho medo disso", você vai falar: "tem cura", mas lá no fundo sempreo associa com a morte (Camila).

E studo com famílias de portadores de câncer em fase terminal identificou que a doença é percebida como incurável, perigosa e horrível, por provocar a morte após longo sofrimento e, com isso, transtornos em todo o contexto familiar ${ }^{(16)}$. N 0 entanto, outro estudo que investigou as percepções de familiares sobre a dinâmica de suas famílias após o câncer de mama na mulher, revel ou que os familiares possuem uma capacidade fluida, elástica, de se adaptar às mudanças, pois a doença propiciou 0 crescimento dos membros individualmente e do grupo como um todo ${ }^{(17) .}$

Contudo, neste estudo constatamos que apesar de os familiares lidarem bem com a situação, 0 câncer ainda traz preocupações:

$P$ enso que temos que fazer a prevenção, porque 0 câncer para mim ainda écomplicado, porquea pessoa pode até estar bem, mas 0 tratamento é muito sofrido. P or mais quea pessoa tenta ficar bem émuito difícil. Q uando fala em câncer, ainda penso em morte (Filha de Alessandra).
T ais concepções se fazem presentes, porque 0 significado atribuído ao câncer ainda é de uma doença que ameaça a vida. E studo com mulheres portadoras de neoplasias da mama e seus familiares sobre concepção do câncer, constatou que as definições mais radicais correlacionando o câncer com doença fatal e a um terrível sofrimento, foram descritos por famílias quejá haviam tido casos de morte pela doença, de pacientes com metástase ou em fase terminal ${ }^{(18)}$.

\section{CONSIDERAÇÕES FINAIS}

A creditamos que esse processo - a convivência com o fantasma do câncer - possa ser relevante para a literatura, uma vez que visual iza o continuar a vida já tendo experienciado o câncer, que também traz mudanças no viver em família. Observamos que realizar exames para detecção precoce da doença é uma atitude val orizada pel as muIheres e seus familiares, o que leva à real ização de exames preventivos periodicamente, instituindo essa prática como uma rotina de vida.

M esmo as mulheres que terminaram o tratamento há al gum tempo e que, de certa forma, sentem que ganharam a batal ha contra o câncer, vivem em um estado de alerta com relação à doença, porque ainda continuam sentindo medo do aparecimento de uma metástase. Este medo relaciona-se a uma mudança de significado da doença, que passa a ser percebida como um "fantasma" queronda a trajetória de vida das mulheres e de seus familiares. Porém, elas revelaram que a convivência com o câncer pode ser harmônica, desde que se realizem os exames e exista possibilidade de procurar um profissional sempre que forem percebidas alterações em seus corpos.

Assim, a enfer magem e os profissionais da área da saúde necessitam atentar para essa fase, em que as pessoas ainda necessitam de acompanhamento direcionado e periódico, porém não apenas através dos exames laboratoriais e de imagens, mas sim por meio de apoio psicológico e emocional, para que essa convivência se tor ne o mais amena possível.

\section{REFERÊ NCIAS}

1 Corbellini VL. Câncer de mama: encontro solitário com o temor do desconhecido. Rev G aúcha E nferm. 2001;22(1):42-68. 
2 Helman CG. Cultura, saúde e doença. Porto A legre: A rtmed; 2003.

3 T avares JSC, T rad LAB. M etáforas e significados do câncer de mama na per spectiva de cinco famílias afetadas. Cad Saúde Pública. 2005;21(2):426-35.

4 M olina-Salci M A. Enfrentando o câncer em família [ dissertação] . M aringá: D epartamento de E nfermagem, U niversidade E stadual de M aringá; 2005.

5 Blumer $\mathrm{H}$. Symbolic interactionism: perspective and method. Englewood Cliffs: Prentience-H all; 1969.

6 G laser BG, Strauss AL. T he discovery of G rounded Theory: strategies for qualitative researsh. Chicago: Aldine Publishing; 1976.

7 G imenes M G G, Queiroz E. As diferentes fases de enfrentamento durante o primeiro ano após a mastectomia. In: G imenes M G G, organizador. A mulher e o câncer. Campinas: Livro Pleno; 2000. p. 173-96.

8 Salci M A, M arcon SS. D e cuidadora a cuidada: quando a mulher vivencia o câncer. T exto Contexto Enferm. 2008;17(3):544-51.

9 Santos GC, G onçalves LLC. M ulheres mastectomizadas com recidiva de câncer: o significado do novo ciclo de quimioterapia. Rev E nfer m U ERJ. 2006;14(2): 239-44.

10 Camargo T C, Souza IE O. A tenção à mulher mastectomizada: discutindo os aspectos ônticos e a dimensão ontológica da atuação da enfer meira no H os- pital do Câncer III. Rev Latino-Am Enfermagem. 2003;11(5):614-21.

11 Siqueira K M , Barbosa M A, Boemer M R. 0 vivenciar a situação de ser com câncer: alguns des-velamentos. Rev Latino-Am Enfermagem. 2007;15(4):605-11.

12 Fernandes AFC. Câncer de mama: mulheres que sobreviveram. Fortaleza: E ditora U F C; 2003.

13 A Imeida A M , M amede M V, Panobianco M S. Construindo o significado da recor rência da doença: a experiência de mulheres com câncer de mama. Rev Latino-A m E nfer magem. 2001;9(5):63-9.

14 T rincaus M R. A morte em seu mostrar-se ao paciente oncológico em situação de metástase [ dissertação] . R ibeirão Preto: E scola de E nfermagem de R ibeirão Preto, U niversidade de São Paulo; 2005.

15 Rzeznik C, Dall'A gnol CM . (Re) descobrindo a vida apesar do câncer. Rev G aúcha Enferm. 2000;21(n esp):84-100.

16 Santana ADA. Cuidados paliativos ao doente oncológico ter minal em domicílio: representações sociais da família [ disser tação] . Salvador: E scola de E nfermagem, U niversidade Federal da Bahia; 2000.

17 Biffi RG, M amede M V. Dinâmica familiar: percepção de famílias de sobreviventes de câncer de mama. E sc Anna Nery Rev Enferm. 2009;13(1):131-9.

18 T avares J SC, T rad L AB. M etáforas e significados do câncer de mama na per spectiva de cinco famílias afetadas. Cad Saúde Pública. 2005;21(2):426-35.

\section{Endereço da autora / Dirección del autor / Author's address:}

M aria A parecida Salci

Av. Colombo, 5790, bloco 01, sala 06,

Jardim U niversitário

87020-900, M aringá, PR

E-mail: masalci@uem.br
Recebido em: 06/ 07/ 2009

A provado em: 20/ 10/ 2009 